\title{
THE TECHNOLOGY OF THE ION CYCLOTRON RANGE OF FREQUENCIES*
}

\author{
D. J. HOFFMAN and G. C. BARBER
}

Oak Ridge National Laboratory

CONF-881031--7

Oak Ridge, TN 37830

DE88 016809

(615) 574-1119

\section{ABSTRACT}

Plasma heating in the ion cyclotron range of frequencies (ICRF) is the least expensive means of accomplishing auxiliary heating in fusion experiments. RF systems comprise two major elements: the transmitter and the antenna. The state of the art for the transmitter is already at the megawatt level. The technology of the antenna is strongly coupled to the plasma character. Typically, these antennas are designed to operate at a high power density $\left(1.2 \mathrm{~kW} / \mathrm{cm}^{2}\right)$ with an efficiency of $96 \%$. ICRF technology and options have improved over the past few years, owing to development and experiments; however, the optimal combination of options can be defined only when results from confinement experiments and test facilities are in hand.

\section{INTRODUCTION}

Several years ago, various experiments showed that ICRF heating was potentially an attractive alternative to neutral beam heating. ICRF was considered because it could (theoretically) heat the core of the plasma, it was relatively inexpensive, it was reliable, it required that only simple structures be close to the plasma, and its large subsystems could be distant from the tokamak. However, the technology of the time was not very advanced. Antennas were mounted to the vacuum vessel and could only sustain low-power short pulses. Studies ${ }^{1}$ showed that ICRF was plagued by problems, including vacuum feedthrough breakdown, other arcing problems in the antenna, and matching element limitations. A number of technological improvements have made it possible to conduct experiments at substantially higher power for longer pulses.

Heating experiments using ion cyclotron waves on the Joint European Torus (JET), ${ }^{2}$ the Princeton Large Torus (PLT),3 TEXTOR, 4 ASDEX,5 and JT-606 have shown that

* Research sponsored by the Office of Fusion Energy, U.S. Department of Energy, under contract DEAC05-84OR21400 with Martin Marietta Energy Systems, Inc. 
ICRF can successfully heat large, fusion-like plasmas. In fact, the world's record for central $n T \tau\left(2.2 \times 10^{20} \mathrm{keV} \cdot \mathrm{s} \cdot \mathrm{m}^{-3}\right)$ was obtained on JET with $8 \mathrm{MW}$ of ICRF. A number of other machines, including the Tokamak Fusion Test Reactor (TFTR), ${ }^{7}$ Tore Supra, 8 Doublet III-D9 (DIII-D), and the Princeton Beta Experiment, 10 are starting to carry out experiments with high-power fast waves or ion Bernstein waves for plasma heating, thereby extending the physics basis for ICRF. Future confinement devices, including the Compact Ignition Tokamak (CIT) and Alcator-CMod, ${ }^{11}$ also call for multimegawatt levels of ICRF to serve as the primary heating method.

The total heating systems required for these machines operate at high power (10-30 MW) for long pulses (2-210 s) in the radio and television range of frequencies (from 30 to $110 \mathrm{MHz}$ ). Generally, the larger machines need higher values of these three parameters because of their larger volume, longer confinement times, and higher magnetic fields. These requirements lead in the direction of more technical difficulty; in addition, the cost of running large experiments demands that reliability be maximized. Despite these constraints, the performance and results of existing ICRF heating systems can scale quite reasonably to a device such as CIT.

The individual heating modules for CIT ${ }^{11}$ will be sized at approximately 2 to $2.5 \mathrm{MW}$. Figure 1 shows the layout for such a modular system; the total power requirement is met by duplicating this system $n$-fold, as appropriate. This layout is used in existing systems; the only difference is that the power levels range from 1.5 to $3 \mathrm{MW}$. The efficiency of the system from dc power through the antenna is approximately $64 \%$, with the bulk of the power losses in the transmitter. However, the efficiency of converting launched power into plasma heating is typically $80 \%$, so the total efficiency is $51 \%$.

In assessing the technology of ICRF, it is important to identify both simple and difficult aspects. Rather than detailing subsystems for which the technology is well in hand, we make some comparisons with the status of other technologies. One significant advantage of If heating systems (including lower hybrid and electron cyclotron heating systems) is the ease of transporting power from the source to the heating site. Bulky dc power supplies and transmitters can be located far from the device itself, where room is at a premium. The transmission of ICRF power is especially easy because the losses in low-frequency, coaxial waveguide transmission systems are 10 to 100 times lower than those in simple high-frequency waveguide systems. Because of these low losses, transmission is not complicated by the expensive, troublesome overmoded techniques required for electron cyclotron systems. In addition, the instrumentation and control (I\&C) and dummy load subsystems require little or no development. At present, they are tailored for the needs of 
the particular application.

The two major areas of recent and future development are the transmitters and the antennas. Transmitter development has borrowed heavily from the technology of the broadcast industry. However, power levels for ICRF heating systems are higher than those required for most broadcast systems; thus, the major development has been the extension to high power. These power levels have been attained on many experiments for relatively long pulses ( $30 \mathrm{~s}$ to $\mathrm{cw}$ ) at frequencies somewhat lower than those ultimately needed for CIT.

The development of ICRF antennas has been carried out almost entirely within the realm of fusion research. Because of the close coupling of antennas to the plasma and the strong interplay between antenna and plasma performance, development has focused on evolving design techniques that can be verified on facilities but must ultimately be proven in the confinement experiment.

\section{TRANSMITTERS}

The state of the art in transmitters is well on the way to meeting the future requirements for fusion. The transmitters envisioned for CIT must be able to produce 2 to $2.5 \mathrm{MW}$ at 80 to $110 \mathrm{MHz}$ for $>10 \mathrm{~s}$. The United States has made considerable progress toward that goal by upgrading the $600-\mathrm{kW}, 80-\mathrm{MHz}$ transmitter for the Fusion Materials Irradiation Test (FMIT). The first step was executed by Continental Electronics; the transmitter power was increased to $1.5 \mathrm{MW}$ (with the Eimac X-2170D tube) for 30 s over a frequency range of 40 to $80 \mathrm{MHz}$ for use at Oak Ridge National Laboratory (ORNL). This upgrade, named the 821-D transmitter, 12 is now the basic building block for numerous if experiments in the United States, including TFTR, CMod, DIII-D, and CIT.

The Continental Electronics 821-D transmitter, shown in Fig. 2, consists of four cascaded amplifier stages. The first stage is a solid-state broadband amplifier. The other three stages are tuned cavity vacuum tube amplifiers in a cathode-driven, grounded-grid configuration. The grounded-grid configuration was chosen because of its stability. Neutralization, a major requirement for stability, is difficult to achieve over the wide frequency range in a grid-driven amplifier system. However, greater stability is achieved at the cost of lower amplifier gain. Although more drive is required, it is not wasted, because 75 to $90 \%$ of the drive is fed through to the output of the driver amplifier stage. Thus, the stability and reliability of the grounded-grid system were gained at the modest cost of the inconvenience involved in tuning more cascaded amplifiers. 
The power supplies for the last two amplifier stages were modified for maximum compatibility with existing subsystems. The final power amplifier plate supply consists of two full-wave-rectified, three-phase, delta- $Y$ secondaries in series. The driver amplifier plate supply is derived from the midpoint of the two rectified secondaries. Each supply is equipped with a crowbar unit to protect the vacuum tubes when fault conditions occur.

The Contintenal 821-D was first tested into a If dummy load at several frequencies and then used to power various tests at the ORNL RF Test Facility (RFTF). Table 1 shows the typical parameters for $1.5-\mathrm{MW}$ power output. The measured harmonics generated by the transmitter into the load (and larer into the antennas, etc.) were more than $40 \mathrm{~dB}$ below the 1.5-MW fundamental power. The total transmitter efficiency, including power supplies, was $\approx 65 \%$ at full power.

The transmitter was used at the RFTF in a variety of tests at many frequencies and power levels. Reliable, stable operation was mandatory because some of the test items are of considerable value. The transmitter was recjuired to run, without oscillation, at power levels ranging from $0.1 \mathrm{~W}$ to $\approx 700 \mathrm{~kW}$. Pulse lengths ranged from $0.01 \mathrm{~s}$ to $\mathrm{cw}$. Under this wide variety of powers, pulses, and frequency, the design showed the necessary reliability for the basic building block of the U.S. ICRF programs.

The 821-D transmitter was designed with provisions to meet the high-power needs of the future. It is completely socket-compatible with the 2.25-MW developmental Eimac X2242 tube, which has high-temperature graphite grids. This tube was recently operated to $2 \mathrm{MW}$ in a transmitter similar to the 821-D for DIII-D. Two transmitter units incorporating the new tube will be used on TFTR in the near future. The total cost of the complete transmitter system, including the nonrecurring engineering cost, is less than $1 \$ / W$ when amortized over the two TFTR units and the ORNL unit. The conversion to the higher frequencies required for CIT will require a similar engineering effort with similar total costs.

\section{ANTENNAS}

The antennas are the critical element of the ICRF system; they must survive the plasma environment while conveying the power to the plasma. An antenna comprises a Faraday shield (which serves as the interface between the anterna and the plasma), the main coupling loop with its housing, the vacuum feedthrough, and any internal matching systems. Figure 3 is a schematic of the 4-MW Bay L antenna ${ }^{7}$ used on TFTR. In this arrangement, the loop is fed in the middle of the strap and terminated by two matching 
capacitors. Complete impedance matching is achieved by this scheme. In front of the current strap is a Faraday shield, consisting of cooled tubing elements with a graphite plasma interface to minimize the effects of impurities. The entire structure fits through a port (in this case $60 \mathrm{~cm}$ by $90 \mathrm{~cm}$ ), thereby facilitating installation, remote maintenance, and antenna positioning. Although the antennas used throughout the world differ in detailed configuration, all of the inductive antennas have features similar to those shown here. The cost of these antennas is generally $\leq 0.50 \$ / W$.

Electrically, the critical element of the antenna is the current strap. While it can be optimized for the precise current and voltage limits, fundamental coupling is the result of powering it with currents in the range of $1 \mathrm{kA} \mathrm{rms}$ and voltages in the range of $50 \mathrm{kV}$ peak. Figure 4 shows a general electrical diagram. The power is given by

$$
\left.P=\text { minimum }\left\{0.5 \cdot\left(\Delta V_{\max }\left[\omega L_{\mathrm{eff}}\right)\right]^{2} R_{\mathrm{eff}}, I_{\max }{ }^{2} R_{\mathrm{eff}}\right)\right\}
$$

where $\Delta V_{\max }$ is the maximum peak voltage to ground, $L_{\mathrm{eff}}=[(Z \tan \beta l) / \omega], R_{\mathrm{eff}}$ is the effective coupling to the plasma, and $I_{\max }$ is the rms current through the strap. The power is maximized by increasing voltage limits, current limits, or coupling. The antennas of JET, TFTR, Tore Supra, the Advanced Toroidal Facility (ATF), ${ }^{13}$ and JT-60 are balanced so that one end of the antenna is at $+\Delta V / 2$ and the other end is at $-\Delta V / 2$, giving it a fourfold gain in the power limitation by voltage. If the antenna is center fed, matching can be accomplished by either capacitive structures or by shorted stubs. The maximum voltage is on the matching structure and is confined to that region. Machines with matched antennas include ATF, TFTR, and Tore Supra. If the antenna is end fed, matching must be accomplished externally. While this has the advantage of placing the matching structure where maintenance is easy, it also expands the regions of high currents and voltages. Furthermore, the maximum voltage is generally placed on the vacuum feedthrough. JET, ASDEX, TEXTOR, JT-60 and one of the TFTR antennas have this matching arrangement.

No matter what matching scheme is used, extending voltage and current limits and coupling increases power limits. Current is generally increased in one of two ways: by increasing cooling at the high-current points or by decreasing the current density at these points. It is relatively easy to get $1-\mathrm{kA}$ capability for 2 -s pulses, but 30 - to 210 -s pulses require the cooling to be engineered, as in the Tore Supra antenna. Increasing the voltage is a bit less straightforward, since it is a function of geometry and materials. Nonetheless, developments in high-voltage vacuum feedthroughs ${ }^{14}$ have brought the state of the art from $20 \mathrm{kV}$ in 1982 to $>60 \mathrm{kV}$ now. The capacitive structures have also been increased from 30 
$\mathrm{kV}$ to $>60 \mathrm{kV}$ pulsed and $55 \mathrm{kV}$ for $40-\mathrm{s}$ pulses. Finally, it is also important to increase the coupling or $R_{\text {eff }}$. Increasing the inductance will naturally increase the flux linkage; however, there is no gain in power because the improvement in coupling is offset by the higher inductance. Slotting the antenna stricture can improve flux linkage, but opens up the antenna to the toroidal flow of plasma. One of the antennas for TFTR is slotted to test this concept.

The Faraday shield is the primary plasma interface. It must shield the antenna from the plasma, protect the plasma from exposure to antenna materials, and (partially) polarize the wave. Studies have shown that it can be configured to effectively pass the wave through the structure to the plasma and have quantified how much it polarizes. 15 The function of protecting the plasma from exposure to easily sputtered if materials like copper or silver is readily achieved by its configuration.

The shield's most difficult task is to directly face the plasma environment. Although the machine limiters take the bulk of the heat flux, the shield must sustain radial plasma flux, direct if losses, and radiation. The heat fluxes may reach a maximum of about $150 \mathrm{~W} / \mathrm{cm}^{2}$. For long-pulse machines such as Tore Supra, this necessitates active cooling. The sides of the shield need some protection since the toroidal thermal flux may be as high as $1 \mathrm{~kW} / \mathrm{cm}^{2}$. This is accomplished by graphite bumpers that surround the antenna.

The choice of the optimum materials to face the plasma is still an area of active research. In general, silver and copper are not acceptable because of they can be sputtered into the plasma and cause high- $Z$ radiation. Materials that have been tried include stainless steel, Inconel, nickel, molybdenum, titanium carbide coatings, boron coatings, "carbonized" coatings, and graphite. As the thermal loads increase, molybdenum and Inconel are being favored as base materials because of their strength. The coatings have been thin, but increasing disruption heat loads $\left(\approx 50 \mathrm{~J} / \mathrm{cm}^{2}\right.$ in less than $20 \mathrm{~ms}$ ) have changed this; at present they are generally required to be 1 to $2 \mathrm{~mm}$ thick. The selection of the best material will be based on minimization of impurity radiation. Experiments imply that bare metals are not optimal, but the various coatings are just starting to be used and cannot be assessed yet.

One area of continuing development that affects the overall design of antennas is the disruption force on the structure. These forces result from eddy currents (induced by disruptions) in the antenna, crossed with the various machine magnetic fields. Generally, they scale with toroidal magnetic field and plasma current. The antennas for Tore Supra and TFTR are designed to handle disruption-induced6 tonne-meters. To date, the materials have been made strong enough to cope with the loads by brute-force techniques. 
However, the forces are expected to more than triple for CIT. DC breaks may be needed at critical sites in the housing and Faraday shield mounting; techniques to break the eddy current are being used successfully on the JET antenna.

\section{FUTURE CONSIDERATIONS FOR ANTENNAS}

As fusion experiments progress to CIT, research must be extended to cope with the tougher plasma environment. As previously discussed, there is always room for higher current and voltage limits. Matching methods must be optimized through continued experiments at high power. Selection of the appropriate Faraday shield materials requires an expanded database for the best decisions. Methods of reducing disruption forces must be proven. All of these problems require results from present and future research. However, some issuts will be encountered only on CIT or the International Thermonuclear Engineering Reacior (ITER). They fall into three classes: additional, harsh environmental or machine constraints that have not yet been faced on a confinement device; additional demands for antenna function; and potential attractive options that scale favorably to these large, high-field machines.

In machines with $Q>1$, ICRF heating systems will face energetic neutron bombardment and have to meet requirements for tritium compatibility and remote maintenance. The primary method of preventing radiation damage in antennas is to have all-metal structures, with line-of-sight lead shielding protecting the vacuum feedthroughs. The problem of tritium compatibility is being addressed on TFTR. Generally, this requires double enclosure on vacuum boundaries. This is accomplished by using some the available port space for enhanced protection. Tritium also creates an implicit demand for high reliability, which is met by more up-front testing and final inspection. The principles of remote maintenance have been partially developed in the "compact loop" approach 16 used on the antennas for ATF, DII-D,17 TFTR, and Tore Supra. Modular antennas, which can be completely installed in a port, can be easily removed and replaced as necessary. Although approaches that facilitate solutions to all of these problems exist, it is necessary to see that the principles and details of future design are effective.

The primary scheme for ICRF in future machines is based on some form of the loop antennas. However, as the frequency of ICRF increases and as the port size increases, waveguides become more attractive. Even with a 0.75 -m-wide port and frequencies in the $100-\mathrm{MHz}$ range, the antennas cannott be simple rectangular waveguides because the fundamental mode cannot be supported. Two techniques to "contract" the toroidal width of 
the wave have been developed: capacitive loading, as in the ridge waveguide, and folding, as in the folded waveguide. Some low-power experiments 18 have been performed on PLT with $\mathrm{TiO}_{2}$ loaded ridge waveguide, which showed coupling like that of the loop. The main attractive features of waveguides are that they can easily hide ceramics from neutron exposure, they have low internal electric fields, and they may not need Faraday shields. Figure 5 show's the configuration of the folded waveguide, 19 with an all-metal, simple structure. It is operated with a half-wave resonance axially, and the adjustable tap point on the vane effects the matching. A test version has been built and run at $30 \mathrm{~kW}$ unloaded, with voltages and currents equivalent to $1 \mathrm{MW}$ loaded in vacuum.

The final new direction for ICRF technology research is in the area of spectral control and antenna phasing. ITER plans call for some form of steady-state current drive. This requires some antenna phasing to generate a directional wave. The same principles can be used to better control heating. The main development issue is how to control highly coupled antenna arrays. To date, the antenna pairs in JET, TFTR, and JT-60 have only tried to generate 0 or $\pi$ phasing. The mutual interaction between loops makes it more difficult to get intermediate phasing. The design of the antennas for Tore Supra and TFTR facilitates intermediate phasing by minimizing the adjacent straps' mutual inductance. Another approach is continuous operational control of the phase and power fed to each radiating element, thereby compensating for the straps' power-dependent impedance.

\section{CONCLUSIONS}

The outlook for ICRF technology is generally optimistic: actual high-power tokamak experiments are giving us the confidence to rely on ICRF heating. ICRF is inexpensive, easily transported power. The technology and physics have made considerable progress toward the ulimate application. In the process, the detailed development needs are being uncovered and addressed with sound experimental bases. The transmitters are in good shape, with some engineering needed to increase the frequency and power level. The development of the antennas is progressing toward the goals of high-power, long-pulse operation, but extension to machines such as CIT requires data from the applications and further development so that the optimum combination of design features can be chosen.

\section{ACKNOWLEDGMENT}

The authors thank J. R. Faulkner of Continental Electronics for his contributions on the 
high-power transmitter and development tube.

\section{REFERENCES}

1. W. R. BECRAFT, ed., "The National RF Technology Research and Development Program Plan," CONF-820758, Oak Ridge National Laboratory, 1982.

2. J. JACQULNOT et al., "High Power ICRF in JET," presented at the 15th European Conference on Controlled Fusion and Plasma Heating, Dubrovnik, May 1988; to be published in Plasma Physics and Controlled Fusion, 1988.

3. J. R. WILSON et al., "ICRF Heating on the PLT Tokamak", Radiofrequency Plasma Heating: AlP Conf. Proc., 129, 28 (1985).

4. J. M. BEUKEN et al., "Comparison of ICRH Heating Scenarii and Antenna Configurations", Proc. 15th European Conf. on Controlled Fusion and Plasma Heating, Dubrovnik, Yugoslavia, 1988, Vol. 12B, Part II, p. 774, European Physical Society, (1988).

5. K. STENMETZ et al., "ICRF H-Mode and $2 \Omega_{\mathrm{CH}} / \mathrm{D}(\mathrm{H})$-Minority Heating on ASDEX," Proc. 13th European Conference on Controlled Fusion and Plasma Heating, Schliersee, FRG, Vol. 10C, Part II, p. 21, European Physical Society (1986).

6. M. SAIGUSA et al., "Coupling Properties of ICRF 2X2 Loop Antenna in JT-60," Applications of Radio-Frequency Power to Plasmas: AIP Conf. Proc., 129, 282 (1987).

7. D. J. HOFFMAN et al., "The Antennas for TFTR," Proc. 15th European Conf. on Controlled Fusion and Plasma Heating, Dubrovnik, Yugoslavia, 1988, Vol. 12B, Part II, p. 770, European Physical Society (1988).

8. W. R. BECRAFT et al., "Compact Loop Launcher Design Study of Tore Supra," Proc. 13th European Conference on Controlled Fusion and Plasma Heating, Schliersee, FRG, Vol. 10C, Part II, p. 161, European Physical Society (1986).

9. M. J. MAYBERRY et al., "Ion Bernstein Wave Heating Experiments on DIII-D," 
Bull.Am. Phys. Soc., 32, 1811 (1987).

10. M. ONO et al., "Ion Bernstein Wave Heating and Lower Hybrid Current Drive Experiments on PBX-M," Bull. Am. Phys. Soc., 32, 1900 (1987).

11. D. W. SWAIN and J. J. YUGO, "Planning for US Ion Cyclotron Heating Research Releveant to the Compact Ignition Tokamak and Alcator C-Mod," ORNL/TM-10464, Oak Ridge National Laboratory (1986).

12. J. R. FAULKNER, Continental Electronics, private communication.

13. F. W. BAITY et al., "ICRF Heating on ATF," Applications of Radio-Frequency Power to Plasmas: AJP Conf. Proc., 129, 32 (1985).

14. F. W. BAITY et al., "ICRF Technology Development Activities ai ORNL," Proc. 13th European Conference on Controlled Fusion and Plasma Heating, Schliersee, FRG, Vol. 10C, Part II, p. 157, European Physical Society (1986).

15. D. J. HOFFMAN et al., "Material and Electromagnetic Properties of Faraday Shields for Ion Cyclotron Heating Antennas," Fusion Technol., 8, No. 1, Part 2A, 392 (1985).

16. D. J. HOFFMAN et al., "Experimental Measurements of the Ion Cyclotorn Antennas' Coupling and RF Characteristics,"Fusion Technol., 8, No. 1, Part 2A, 411 (1985).

17. P. M. RYAN et al., "Analysis of Plasma Coupling with the Prototype DIII-D ICRF Antenna," Proc. 15th European Conf. on Controlled Fusion and Plasma Heating, Dubrovnik, Yugoslavia, 1988, Vol. 12B, Part II, p. 795, European Physical Society (1988).

18. G. J. GREENE, "ICRF Coupling with a Ridged Waveguide on PLT" Applications of Radio-Frequency Power to Plasmas: AIP Conf. Proc., 129, 322 (1985).

19. T. L. OWENS et al., "Tests of a High Power Folded Waveguide Coupler for ICRF Heating", ICRF Coupling with a Ridged Waveguide on PLT," Applications of RadioFrequency Pow'er to Plasmas: AlP Conf. Proc., 129, 298 (1985). 


\section{TABLE I}

Typical Parameters for 1.5-MW Operation of 821-D Transmitter

$\begin{array}{lll} & \text { Driver } & \begin{array}{l}\text { Final Power } \\ \text { Amplifier }\end{array} \\ \text { Plate voltage, } \mathrm{kV} & 11.3 & \\ \text { Plate current, A } & 7 & 21.3 \\ \text { Screen voltage, } \mathrm{kV} & 920 & 108 \\ \text { Screen current, A } & 0.65 & 1080 \\ \text { Grid voltage, V } & 550 & 0.3 \\ \text { Grid current, A } & 0 & 620 \\ & & 2.6\end{array}$




\section{FIGURE CAPTIONS}

Fig. 1. ICRF module for CIT,

Fig. 2. The Continental Electronics 821-D transmitter.

Fig. 3. Schematic of the TFTR antenna.

Fig. 4. Antenna electrical layout.

Fig. 5. $80-\mathrm{MHz}$ folded waveguide coupler. 
Fig 1

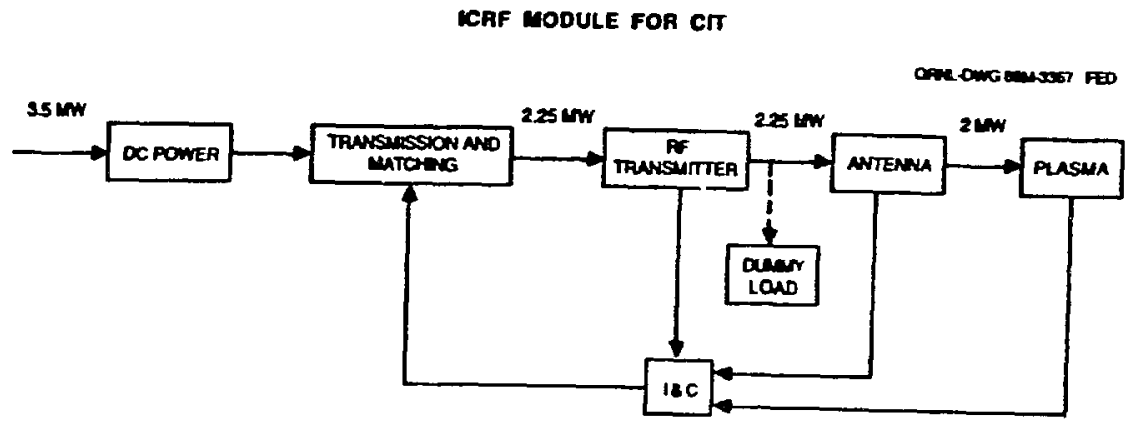



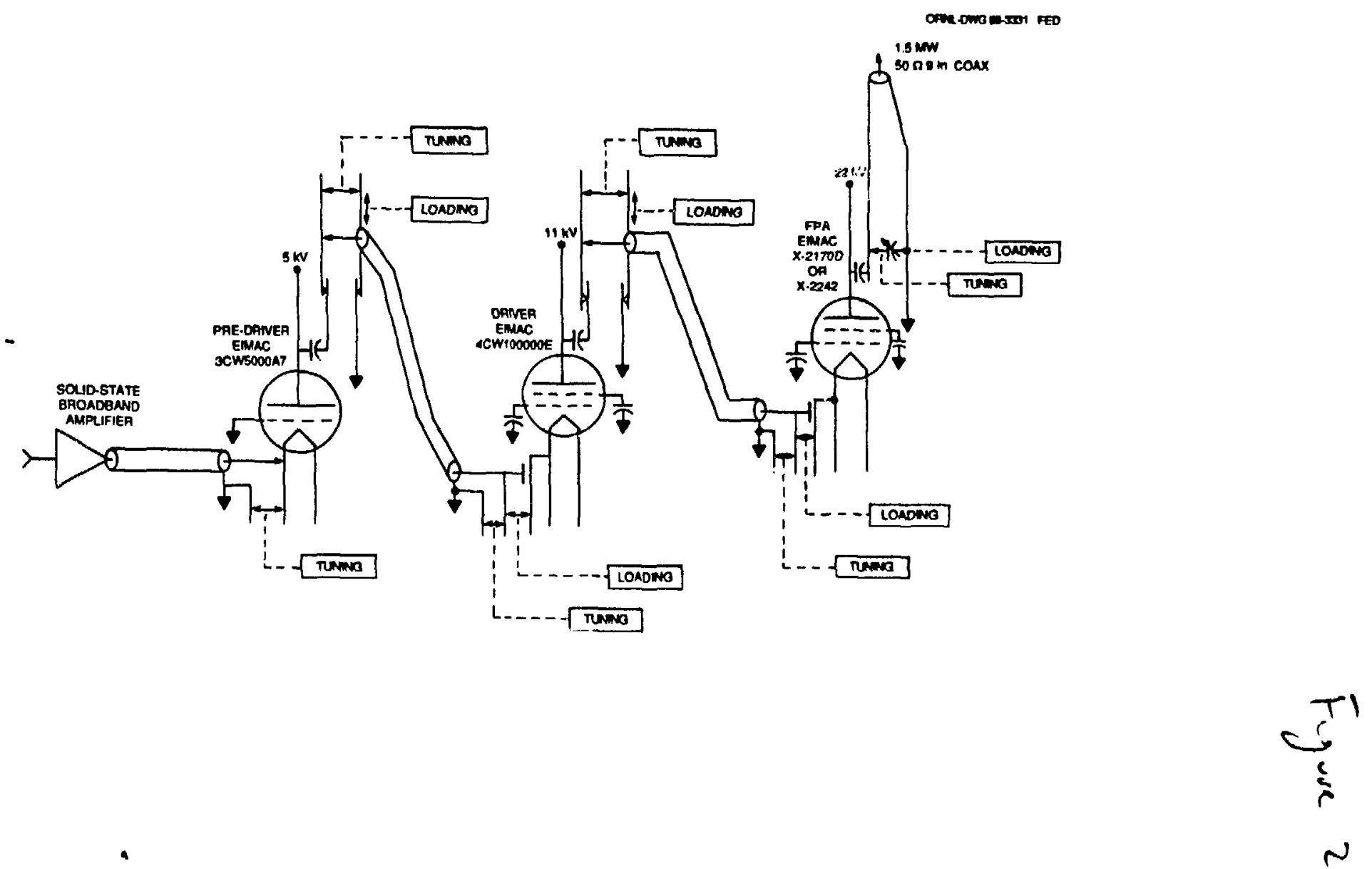


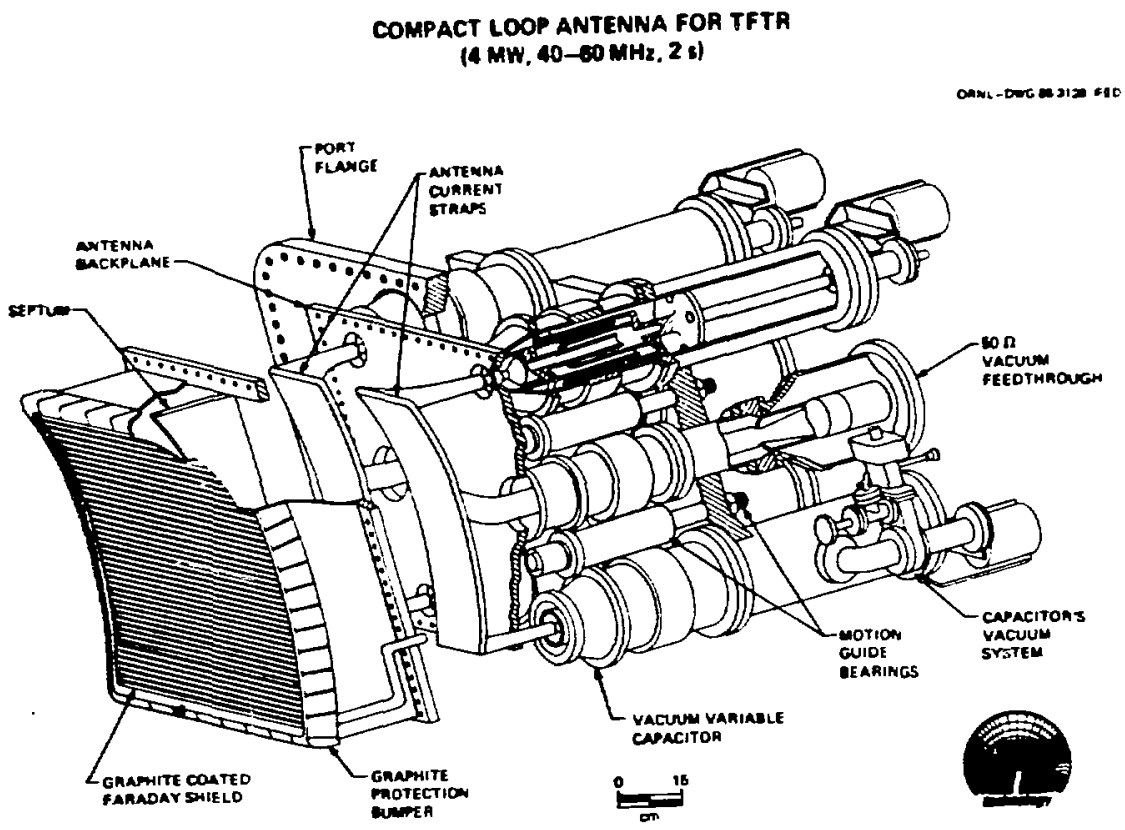




$$
x . q^{u+4}
$$

\section{ANTENNA ELECTRICAL LAYOUT}

OANL-DWG B8M-3368 FED

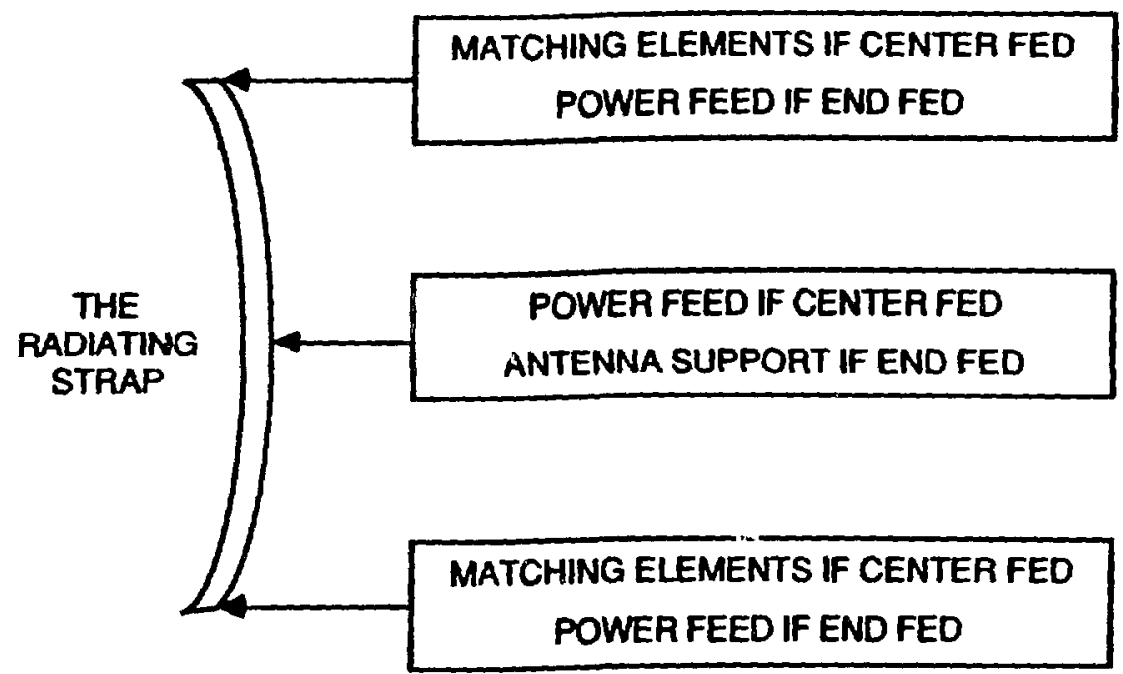




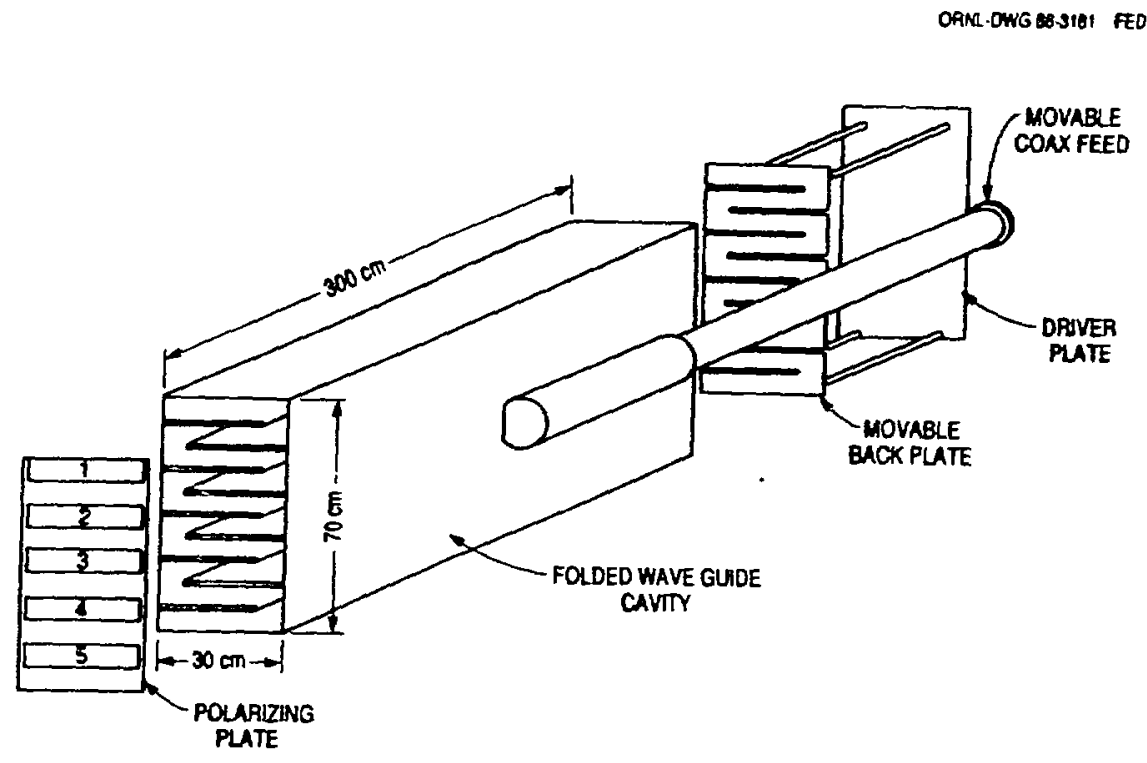

\section{DISCLAIMER}

This report was prepared as an account of work sponsored by an agency of the United States Government. Neither the United States Government nor any agency thereof, nor any of their employees, makes any warranty, express or implied, or assumes any legal liability or responsibility for the accuracy, completeness, or usefulness of any information, apparatus, product, or process disclosed, or represents that its use would not infringe privately owned rights. Reference herein to any specific commercial product, process, or service by trade name, trademark, manufacturer, or otheswise does not necessarily constitute or imply its endorsement, recommendation, or favoring by the United States Government or any agency thereof. The views and opinions of authors expressed horein do not necessarily state or reflect those of the United States Government or any agency thereof. 